\title{
Identidad, pluralidad y valoración de las diferencias
}

\section{Concepción de identidad}

Al hacer referencia a las representaciones de identidad que tienen los docentes, se mencionan varias características, entre ellas, el sentirse identificado con el lugar de donde se es oriundo, o con relación a la personalidad, por ejemplo.

Es como, cómo cuando el ser humano se apropia de algo. Cuando ese algo hace parte de él. Por ejemplo: yo me considero, yo soy Santiaguero. Y... yo... para mí no hay otro pueblo más bonito que Santiago. Con todo lo que tenga, para mí Santiago es... es todo. Es el espacio donde yo... nací, donde... yo... me, me... desarrollé, me crie y donde yo aspiro que, que... quedar aquí, que me entierren acá. (DOC1EI)

En eso podemos también digamos en la identidad podemos meterla lo que juega la personalidad de cada uno de los jóvenes ¿sí? Hay personalidades pasivas, activas. Hay personalidades permisivas. ¿Sí? Y otros que son, se enfadan, se enfadan fácilmente. Entonces también eso tiene mucho que ver, digamos, la identidad de los muchachos. (PROF4GFD) 
Por su parte, los estudiantes asumen la identidad mostrándose ante sus compañeros y profesores a partir de sus actuaciones y desempeños.

¿Identidad cuando uno se da, cuando uno se da no a conocer no...? como a mostrar como yo soy esta persona. ¡O sea, yo soy disciplinado que yo soy respetuoso y que a uno no lo tomen como no! Que este pelao es gamín, que este "pelao" es esto, que este "pelao" es aquello, para mí eso es lo que entiendo como identidad. (E1EI)

De pronto como uno se comporta en el colegio, como dice la compañera. Si yo tengo una personalidad en el colegio y todos me conocen, algunos me conocerán. ¡No! Aquel “man” es bien, aquel "man" es mal. Según como uno se comporte en el colegio, lo reconocen los profesores y los mismos compañeros de uno. (AL2GFES)

De las opiniones de los informantes se identifica, como lo proponen Chaux et al. (2004), que la identidad es la visión que cada persona tiene de sí no solo como individuo, sino también como miembro de grupos sociales o, inclusive, de naciones, por lo que un ciudadano competente no solamente reconoce sus múltiples identidades, sino que reconoce y valora las de los demás.

Se puede establecer, además, como lo destaca Bernal (2004), la "identidad personal" comprendida como un proceso eminentemente dinámico porque en el curso de la vida misma los elementos configuradores de la identidad pueden modificarse. Bernal considera que en todo este proceso se produce un movimiento hacia la segregación, hacia la independencia, hacia la individuación, que resulta básico para llegar a construir la identidad personal.

\section{Identidad como sentido de pertenencia}

Un factor paralelo a la concepción de identidad está relacionado con la pertenencia a un grupo, a una organización, a un colectivo que tenga características similares para poder ser reconocido socialmente. Los docentes se refieren a esto como el sentido de pertenencia. 
Lo mismo el colegio es, es... el escenario donde yo estoy, que me aporta... gracias que el señor me da a mí para comer para vivir. Entonces yo estoy identificado. Todo lo que le ocurra al colegio a mí me afecta. Yo siento que me afecta. (DOC1EI)

Y lo relaciono también con el sentido de pertenencia. (DOC2EI)

Mientras tanto, los estudiantes conciben la identidad desde la forma de comportarse en el transcurso de su etapa escolar para ser identificados como estudiantes ejemplares o conflictivos, por ejemplo.

Pues mirando cómo una persona ha sido en el transcurso que ha estado en el colegio. Si ha sido problemático, bien y todo eso. Por ejemplo: han habido problemas de... que culpan a personas que no son. Entonces por esa persona pagan todos y después miran a la persona. ¡No...! ¡Pero yo no... ¡Soy así! Y no importa si tiene el comportamiento bien o mal, le echan la culpa. (AL3GFES)

Es lo que a uno lo representa. La identidad: es como los pensamientos, su forma de ser y sus cualidades. Es la identidad de una persona. (E2EI)

Considerando las ideas de los docentes y estudiantes alrededor del sentido de pertenencia como parte de la formación de identidad, es coherente retomar a Vera (2012) cuando manifiesta que es en este nivel de las relaciones entre el individuo y la realidad cuando se van activando tempranamente mediante la socialización primaria para configurar paulatinamente lo que denomina "la identidad del yo".

Ese sentido de pertenencia mencionado por los informantes está relacionado con la visión que cada persona tiene no solo de sí como individuo, sino también en relación con los grupos sociales a los que pertenecen, como lo anotan Chaux et al. (2004).

De esta manera, Vera (2012) señala que "en términos del lenguaje de las teorías de la personalidad, la estructura en la que se manifiesta subjetiva y objetivamente recibe el nombre de Yo, Ego, Psiqué, Sí 
mismo, o Estructura Cognoscitiva, dependiendo de la escuela de pensamiento" (p. 274).

\section{Se habla de inclusión, pero en la práctica existen vacíos}

Al ser consultados sobre la forma como en el desarrollo de la práctica pedagógica se promueve la inclusión, los docentes consideran que existe una política institucional para ello, pero a la hora de llevarla a la práctica, muchas veces no se ejecuta.

Bueno. Haber, eh... este algo que me... ofende mucho es eso. Porque es que nosotros no podemos... En la de semana institucional estábamos hablando de la convivencia institucional. Y yo decía: ¡Hombre! nosotros no podemos hablar de convivencia, cuando desde las directrices no generamos la convivencia. No podemos hablar de inclusión cuando desde nuestro modo de pensar somos excluyentes. Entonces eso a mí, me pone muy mal porque es que la formación que pretende que... impartamos es una, pero parecemos que a veces caminamos en contravía de esa de esa misma filosofía formativa. (DOC1EI)

Otros docentes asocian la inclusión con el manejo inadecuado de los comportamientos disciplinarios. Consideran que darle libertad a los jóvenes, genera demasiados conflictos.

Dijo: hay profesores que los dejan hacer a los muchachos lo que quieran, que no sé qué... pero le dije: profesor miré... y le conté... le dije todo lo que había dicho el estudiante. Dijo: ¡Ah! Pero yo no vi. Yo no lo vi. ¿Cómo no va ver si estaba al lado de él? Nosotros vemos que como por no llevar, o irse en contra del muchacho, entonces lo dejan a uno que... (DOC2EI)

Las apreciaciones de los docentes hasta aquí pueden asimilarse a los planteamientos de Engelken (2005), quien refiere la capacidad 
explicativa que la identidad tiene sobre ideas y comportamientos y que remite al problema de la (auto) conciencia como variable independiente. Esto puede interpretarse como las ideas que una persona puede tener sobre inclusión, pero que difieren en la práctica por no ajustarse a su propio modo de actuar.

En el momento en que el docente señala que "no podemos hablar de inclusión cuando desde nuestro modo de pensar somos excluyentes”, puede ser comprendido desde Morín (citado en Engelken, 2005) en cuanto sostiene que:

la identidad debe ser entendida en un doble sentido: como epifenómeno, esto es, como aspecto de carácter secundario y dependiente (por lo tanto, "superficial") de los "fondos" biológicos y culturales, y como proceso central de la actividad humana, fruto de la (auto) reflexión y capaz para retro actuar sobre las ideas, el comportamiento y sobre el ser mismo. (p. 275)

Es decir, proponer una acción inclusiva al interior de las instituciones debe ser coherente con la forma de actuar no solo desde los docentes, sino también desde los directivos. Esto, en la medida en que promover competencias como la inclusión implican una profunda autorreflexión que permita establecer cómo se identifica el docente respecto a su talante inclusivo en el ejercicio de su práctica pedagógica.

Entre tanto, los estudiantes, aunque entienden la necesidad de facilitar los espacios para que todos puedan participar y desarrollarse, cuando tocan temas álgidos, como por ejemplo un eventual posconflicto en Colombia, se muestran en su mayoría escépticos e incluso rechazan la posibilidad de otorgar derechos a quienes han sido parte del conflicto: "En debate en clase estudiantes señalan que no es lógico que luego de un proceso de paz, tengan los mismos derechos que quienes siempre han estado en la legalidad, dice una estudiante. Otros compañeros apoyan esta postura" (G200).

García y Mieles (2010), en su trabajo, reflexionan acerca de cómo las sociedades en algunas regiones y ciertas poblaciones se han visto forzadas a abandonar sus sitios de origen y cambiar de residencia, 
viéndose obligados a adaptarse a otras costumbres e iniciar nuevos procesos de socialización que traen problemas en la construcción de identidad, en especial de los niños y niñas, los cuales generan cambios de rol de las familias en la crianza de los hijos.

Tales consideraciones hacen notar que muchas sociedades, empezando por la misma colombiana, se han visto en la necesidad de buscar caminos de reculturización, dados fenómenos como el desplazamiento forzado a causa de la violencia. No obstante, lo que se identifica en las apreciaciones de los informantes clave en esta investigación es que no existe plena conciencia de ello, y, por tanto, se resisten a la posibilidad de aceptar a miembros de una sociedad que hayan pasado por dificultades y hayan tenido que tomar el camino de la ilegalidad, con el argumento de que no sería justo ni equitativo.

Lo manifestado por docentes y estudiantes en este apartado se puede observar a la luz de la teoría de Chaux et al. (2004), quienes señalan que "las competencias emocionales son las capacidades necesarias para identificar y responder constructivamente ante las emociones propias y las de los demás” (p. 25). En este sentido, es necesario fortalecer, en el marco de la práctica pedagógica para el desarrollo de las competencias ciudadanas, competencias como la empatía, dado que por la manera como se expresan y se comportan los estudiantes, adolecen aún de la capacidad para sentir lo que otros sienten o por lo menos sentir algo compatible con lo que puedan estar sintiendo otros.

En la misma línea de Chaux, se requiere adicionalmente trabajar más en el desarrollo de la identificación de las emociones de los demás, entendida como la capacidad para identificar lo que pueden estar sintiendo otras personas tanto por medio de sus expresiones verbales y no verbales, como teniendo en cuenta la situación en la que se encuentran.

\section{Concepción de pluralidad}

Sobre la representación que los docentes tienen de pluralidad en el marco de las competencias ciudadanas, señalaron que la pluralidad involucra la inclusión como posibilidad de convivencia en una misma comunidad: "El ámbito... Pluralismo es un ámbito grande, que incluye, incluye a todas las cosas, así como estamos nosotros aquí como 
somos; gordos, blancos, bajitos, calvos. Entonces eso se llama pluralidad, conjunto de las personas es el pluralismo que hay" (PROF1GFD).

Por su parte, los estudiantes definen la pluralidad como diversidad en una misma comunidad, en este caso escolar: "En el colegio hay pluralidad de estudiantes, pluralidad de docentes, los del servicio, pluralidad del restaurante, pluralidad de la cafetería... Una convivencia" (E2EI).

Para docentes y estudiantes de las instituciones educativas la pluralidad se puede interpretar desde la postura de Fuentes-Navarro (2008), cuando menciona que una comunicación para la inserción, la interacción y la convivencia de los sujetos en un lugar lleno de iguales-plurales-distintos, posibilita la realización de la condición humana, propiamente comunicativa. Y como expresión de pluralidad, para navarro, no es otra cosa que "vivir como ser distinto y único entre iguales” (p. 340). De tal modo lo señala un docente cuando dice que "pluralismo es un ámbito grande, que incluye, incluye a todas las cosas, así como estamos nosotros aquí, como somos”.

Por otro lado, cuando una estudiante dice que "hay pluralidad de estudiantes, pluralidad de docentes, los del servicio, pluralidad del restaurante, pluralidad de la cafetería... Una convivencia”, esta concepción se relaciona en forma directa con la forma de pensar de Bartolomé (2002), cuando expone que el lugar y el momento hacen que el ciudadano en formación se identifique con su comunidad, el Estado o la sociedad general, teniendo en cuenta el multiculturalismo, la diversidad y el surgimiento constante de ideas (p. 131).

\section{Casos de exclusión y discriminación}

Pese a que existen ejemplos relevantes que sirven como muestra de inclusión y de respeto a las diferencias al interior de las instituciones, dado que hay varios estudiantes con limitaciones físicas que reciben apoyo tanto de sus profesores como de sus compañeros, se presentan casos evidentes de discriminación que, si bien no es sistemática, sí reflejan debilidad en el proceso de desarrollo de las competencias ciudadanas. Desde la visión de los docentes, se han dado casos de discriminación cuando se van a desarrollar los procesos de participación democrática. 
Pero se han presentado cosas que van en contravía de eso. Por ejemplo, eh... vamos a elegir los niños representantes al... al gobierno del municipio. Entonces, ¡bueno! vamos a buscar un niño que represente el alcalde. Entonces empiezan: ¡No! Ese niño no porque ese niño no es de aquí, es de Cornejo. Entonces empezamos y a ser excluyentes. Cuando debemos ser lo contrario: todos por igual. En la convivencia los derechos son todos iguales. (DOC1EI)

Para comprender esta actuación, es prudente tener en cuenta la propuesta de Rodríguez (2005) cuando señala que "los conocimientos entendidos como representaciones de la realidad (...) se construyen y acumulan según la formación y experiencia personal, están presentes en casi todas nuestras acciones, ya sean conocimientos elementales, complejos o de sentido común" (p. 70).

Como se observa, no hay el conocimiento suficiente requerido para evitar acciones discriminatorias. Como se puede entender, este planteamiento de Rodríguez (2005) no es aplicable a las instituciones en razón de las expresiones de los miembros de la comunidad: “¡Bueno! vamos a buscar un niño que represente el alcalde. Entonces empiezan: ¡No! Ese niño no porque ese niño no es de aquí, es de Cornejo" (DOC1EI).

Estas formas de actuar evidencian, según Perrenoud (citado en Rodríguez, 2005), una falencia en "la capacidad para actuar eficazmente en una situación definida, haciendo uso de los conocimientos, pero sin limitarse solo a ellos”. Según tal consideración, “para hacer frente a una situación de manera óptima, en general se necesita hacer uso y asociar varios recursos cognitivos complementarios, tales como los conocimientos" (p. 70).

Esto significa que cuando se toman decisiones sobre situaciones que comprometen la participación de los estudiantes no se pondera la necesidad de prevenir que ellos puedan ser objeto de discriminación, así no se tenga la intención directa de hacerlo. Por su parte, entre los mismos estudiantes se reconocen actuaciones discriminatorias que buscan generalmente ridiculizar a un determinado estudiante frente a sus pares. 
Pues haber. Muchas veces sí. Que no respeta las opiniones de los demás, algunos estudiantes dan opiniones y se burlan o... tratan de llevarles siempre la contraria o algún estudiante quiere ser algo y no lo dejan. Tratan de opacarlo o dicen ¡ay no! ¡Otro! y lo someten a votación y ahí es donde no cae. Entonces... (E2EI)

Entre tanto, lo que se pudo verificar en las observaciones en el aula de clase permitió evidenciar situaciones en las que no se le permite a un estudiante participar, o se le critica por cometer un error.

Un estudiante se interesa en participar. Pide la palabra y no se la dan, señalan que ya pasó el tiempo de la exposición. (G202)

Moderadora da indicaciones, se equivoca y piden que la cambien. (G200)

Lo anterior puede interpretarse desde la teoría de Chaux et al. (2004) cuando consideran que "las competencias emocionales son las capacidades necesarias para identificar y responder constructivamente ante las emociones propias y las de los demás”. En estos casos salen a la superficie debilidades relacionadas con la incapacidad de ponerse en el lugar del otro y sentir lo que otros sienten, o por lo menos sentir algo compatible con lo que puedan estar sintiendo otros cuando son objeto de acciones discriminatorias.

\section{Formas de identificar casos de discriminación o exclusión}

La utilización de apodos es una de las principales formas de identificación de casos de discriminación, según lo manifestado por los docentes y los estudiantes, cuando se refieren a la cotidianidad de la vida escolar.

Me acuerdo la niña esta de octavo el año pasado. Ella llegó, venía de otro colegio, y ella llegó con una actitud de participar. Yo 
la observé. Esta "china" pilosa. Cuando de pronto, llegó un momento...No volvió a participar. Entonces yo hablaba con ella: ¿y qué pasó? ¡No...! Es que ellos me pusieron apodo. ¿YY qué? Me llaman: "Wikipedia". Los muchachos le pusieron "Wikipedia" porque ella era la que participaba. Ahí ya se generó un conflicto, y entonces, bueno, se habló con los muchachos, les dije, la niña se, se... cayó totalmente. (PROF6GFD)

Los estudiantes señalan que un compañero o compañera es identificable cuando es objeto de discriminación porque se convierten en estudiantes que prefieren mantenerse alejados de sus compañeros en horarios distintos a las clases.

Cuando a la persona le están haciendo bullying o matoneo aquí las personas como que se decaen. Las personas, o sea, ya se vuelven antisociables. Ellos quieren estar solos. O sea, ellos no quieren hablar con nadie. Dicen sí, pero a la vez no. Pues la persona, o sea, muchos cambian, cambian muchísimo. Ellos se vuelven antisociables y pues, dejan de convivir con los demás por el miedo que le dejen de hacer bullying o matoneo, o... lo que le estén haciendo. (E1EI)

Walzer (1996), al referirse al criterio de Estado-nación, señala como inherente la necesidad de entender la existencia de la escuela como escenario adecuado para promover la valoración de las diferencias y ejercer la tolerancia, además desde una perspectiva de los derechos humanos. Y es que "la escuela es también un escenario en el que se construyen las identidades tanto individuales como colectivas, es decir, los sentidos y lazos de pertenencia que construimos con unos u otros referentes culturales" (MEN, 2004, p. 21).

Así debería tenerse claro y aplicarse al interior de las instituciones educativas, según lo expresan los docentes. Sin embargo, en la realidad, se hacen evidentes los ejemplos de discriminación que terminan afectando el normal desarrollo de los procesos de convivencia escolar como en el caso de la estudiante que tomó la determinación de "autoexcluirse" porque sus compañeros la "tildaron", de "Wikipedia". 
Contrario a lo considerado por Walzer, quien plantea que es necesario comprender "la escuela como una institución social, que forma a los niños, niñas, adolescentes y jóvenes para que tomen decisiones informadas, autónomas, responsables, placenteras y saludables que enriquezcan sus proyectos de vida", en la práctica, las presiones de sus compañeros no permiten que tales decisiones se puedan tomar bajo tales criterios en formal cabal, en esta institución.

El Ministerio de Educación señala desde su visión de derechos humanos que

[...] los grupos humanos en todas las épocas han creado códigos y pautas de comportamiento para organizar la vida en sociedad. Dichos códigos responden a los principios y valores centrales para cada cultura en un momento determinado, se componen de normas derivadas de estos principios, e incluyen derechos y deberes de los individuos y grupos. (p. 21)

Por la evidencia obtenida, las apreciaciones obtenidas de los informantes clave y las acciones observadas en la vida cotidiana institucional, se concluye que la visión de que los derechos humanos son una construcción social, enmarcada dentro de unos determinados contextos políticos y representaciones culturales, sin las cuales su existencia habría sido impensable, deben ser reforzados a través de estrategias más agresivas desde el punto de vista pedagógico, dado que existen muy relevantes dificultades en el ámbito del respeto y la valoración de las diferencias entre los estudiantes de educación media técnica de esta institución.

\section{Competencias integradoras: formas de intervención oportuna}

En torno a las estrategias que son utilizadas tanto por profesores como por estudiantes para atender de manera oportuna y adecuada casos de discriminación que puedan presentarse en el aula de clase o en algún escenario de convivencia distinto en las instituciones, los informantes clave señalaron que una de las acciones es la planeación de actividades 
que fortalezcan el conocimiento sobre lo que es la valoración de las diferencias y cómo pueden potenciarse: “¡Hombre! Eso hay que cortarlo. Eso no se puede permitir. Y aprovechar los espacios de... planeación institucional para... reforzar eso. No se puede permitir" (DOC1EI).

Una estudiante relató un ejemplo de lo que ella hace cuando identifica compañeros que tienen dificultades para ser aceptados por sus pares.

\begin{abstract}
Y yo hace poquito vi a un compañero así decaído. Y yo: ¿Qué tiene? Y cuando, empecé a darle más confianza entonces, llegó y dijo: ¡No! que la vida... no tiene sentido, que la vida es injusta, que la vida hace con uno lo que le da la gana, entonces uno para que le va dar importancia. Entonces yo le dije: ¡No! que no diga eso que la vida si tiene sentido. La vida es una sola. (AL3GFES)
\end{abstract}

Algunas situaciones particulares, observadas en clase, permitieron establecer que siempre el tema de la equidad de género está presente en las conversaciones de los jóvenes estudiantes, aunque las niñas han aprendido a valorarse y a no permitir que se les estigmatice: "Sobre el tema de la clase: el maltrato, alguien pregunta sobre la opinión del sexo débil, algunas compañeras dicen que son más delicadas, pero no más débiles" (G201).

Frente a este aspecto, desde la perspectiva de equidad de género, Panchón (2007) señala que aún hoy "el centro educativo recibe y/o reproduce una cultura androcéntrica, en la que es muy difícil incorporar los puntos de vista y los saberes femeninos". Panchón sostiene que "la escuela sigue siendo todavía una realidad insuficientemente equitativa para las niñas y las adolescentes, en la que aún no se ha conseguido la eliminación de los estereotipos de género", y complementa con que "el primer entorno de responsabilidad educativa es la familia” (p. 159).

Panchón otorga la necesidad de "una profunda reflexión sobre el sistema educativo, la organización de los centros educativos, los contenidos que se imparten, los materiales de las diferentes asignaturas y la formación del profesorado". En este sentido, deposita en los docentes una enorme responsabilidad cuando escribe que "la implicación 
corporativa de los profesionales de la enseñanza va más allá de las posturas personales de algunos profesores y profesoras” (p. 159).

Es de anotar que las instituciones educativas, aunque no están exentas de casos de discriminación, tienen ejemplos relevantes de respeto y valoración por las diferencias, en la medida en que hay varios estudiantes, algunos con limitaciones visuales, otros con limitaciones auditivas y otros cognitivas, que han sido recibidos en el seno del colegio y que al igual que los demás compañeros reciben formación, bajo los criterios de educación inclusiva y a partir de los lineamientos de la población con necesidades educativas especiales.

Este elemento se ajusta a la postura de Chaux et al. (2004), cuando en su estudio definen que "la pluralidad y la valoración de las diferencias es en últimas el reconocimiento, el respeto y la valoración de las múltiples identidades propias y las de los demás”. Además, destacan que "la pluralidad y la valoración de las diferencias no pueden llevar a que se tolere a quienes vulneran derechos fundamentales" (p. 20).

$\mathrm{Al}$ encontrar ejemplos de atención a niños y niñas con necesidades educativas especiales, al interior de las instituciones, se evidencia que, pese a las debilidades identificadas, se logra percibir que existe un grado de manejo de las denominadas competencias integradoras como “competencias más amplias y abarcadoras". Los autores de esta propuesta explican que, en la práctica, tales competencias "articulan los conocimientos y las competencias cognitivas, emocionales o comunicativas" (p. 25), sin desconocer que existen problemas y que deben ser atendidos con responsabilidad y con esfuerzos continuos y sostenidos.

\section{Representaciones de valoración de las diferencias}

Respecto a la representación que tienen los docentes sobre valoración de las diferencias, se destaca la diversidad de personalidades, formas de pensamiento y de actuación que tienen los estudiantes del grado décimo. Hay casos desde estudiantes muy extrovertidos, hasta jóvenes que prefieren mantenerse al margen del grupo. Sin embargo, todos conviven en una relativa tranquilidad a juicio de los docentes consultados. 
Es la aceptación. Por ejemplo, aquí tenemos grados de estudiantes que uno nota que... por ejemplo, el grado décimo es, es... muy muy diverso, es muy diverso. Entonces hay los estudiantes, yo creo que aceptan a un estudiante que nunca sale, que no le gusta la exposición. Se calla, es demasiado quieta esa niña. ¡Sí! Hay una niña, y uno, pues, uno ha tratado dentro de la parte del aprendizaje que ella mejore, pero los estudiantes sí... uno nota que la han aceptado a ella. Que es diferente. Y otra clase de estudiantes que son diferentes entonces los comportamientos también... influyen. (PROF3GFD)

Lo aquí expresado se asume, según Walzer (1996), dado que, en la actualidad, la homogeneidad es un factor inexistente. Por ello el escenario de la escuela como institución se constituye en el espacio oportuno en el que se construyen las identidades tanto individuales como colectivas. Tales identidades hacen parte de los grupos humanos que en todas las épocas han creado códigos y pautas de comportamiento para organizar la vida en sociedad.

Entre los estudiantes, la valoración de las diferencias se concibe con la necesidad de que todos los estudiantes puedan destacarse por sus capacidades, talentos y habilidades, sin que, por sus dificultades, sean excluidos de participar en lo que a ellos les gusta:

O digamos así: digamos aquí hay mucho estudiante que es muy inteligente. Y yo siempre lo he dicho y lo sostengo. ¡Que aquí en este colegio no se toman a la persona que sabe sino por lo que lleve la persona en el cuaderno! O sea, aquí no se toma la inteligencia sino lo que usted escribió en un cuaderno y ya aquí mucho. Aquí ocurre que hay las personas que sí que sacan 5 en el cuaderno que sacan $5 . .$. en los talleres. Que sacan 1.0 en una evaluación y las personas que sacan 3, o sacan 2.0 en el cuaderno sacan siempre 5 en las evaluaciones. Esas personas no las tienen en cuenta, sino que siempre se tienen en cuenta a las personas que llevan siempre digámoslo así, llevan el cuaderno bonito no más. (E1EI) 
Lo expuesto por el entrevistado se puede resumir en la posición de Chaux et al. (2004) cuando advierten que la pluralidad y la valoración de las diferencias es en últimas el reconocimiento, el respeto y la valoración de las múltiples identidades propias y las de los demás, por lo que la pluralidad y la valoración de las diferencias no pueden llevar a que se tolere a quienes vulneran derechos fundamentales. Dichos códigos responden a los principios y valores centrales para cada cultura en un momento determinado y se componen de normas derivadas de estos principios, e incluyen derechos y deberes de los individuos y grupos.

En el trabajo de observación no participante se logró establecer la opinión de algunos docentes, cuando dialogan entre ellos en horario de descanso. Sostienen que sería importante que los estudiantes que tienen tendencias homosexuales deberían manifestarlo para poder darle un trato más equitativo y no a partir de la duda: "Un docente señala que alumnos deberían decir si son de tendencia: 'Homo' o no para saber cómo tratarlos, y no herir susceptibilidades" (GDOC-SP).

$\mathrm{Al}$ respecto, partiendo desde la idea de Estado-nación del cual habla Walzer, es inherente la necesidad de entender la existencia de la escuela como escenario adecuado para promover la valoración de las diferencias y ejercer la tolerancia, además desde una perspectiva de los derechos humanos.

Ahora, desde la perspectiva de equidad de género, Panchón (2007) sostiene que "la escuela sigue siendo todavía una realidad insuficientemente equitativa para las niñas y las adolescentes, en la que aún no se ha conseguido la eliminación de los estereotipos de género" (p. 60). Hoy puede ampliarse esta postura a quienes tienen tendencias sexuales diferentes a las heterosexuales, para señalar que, pese a los esfuerzos por llegar a las aulas con un mensaje de respeto por los derechos sexuales, aún queda mucho por hacer en este sentido.

\section{Promoción del respeto desde los derechos humanos}

Los docentes manifestaron sentirse comprometidos con la necesidad de ejecutar acciones que promuevan el respeto por las diferencias en el ejercicio de su práctica pedagógica. Por ello, manifestaron que habían 
programado una serie de actividades de formación para socializar con los estudiantes.

El 11 de septiembre empezamos unos talleres de competencias ciudadanas precisamente para que los mismos muchachos... Vamos a capacitar a unos muchachos de unos grados, para que ellos vayan y que, a su vez, capaciten a todo el colegio, en diferencia. El colegio está haciendo un trabajo para precisamente mostrar eso: lo que usted está haciendo. Me imagino que todos los colegios están haciendo lo mismo, ¿̇no? Porque es necesario que los muchachos identifiquen sus... a sus otros. Que se identifiquen primero a sí mismos, pero para que puedan identificar a las demás personas que conviven con ellos (PROF2GFD).

La justificación de Lahera (2004), cuando manifiesta que es posible definir una política pública como aquellas acciones dirigidas a mejorar la administración de un tópico nacional y que estas acciones deben ser orientadas por el Estado a través de las instituciones públicas y en el mejor de los casos deben ser apoyados por la comunidad beneficiaria (p. 5), se ajustan oportunamente en la labor que en las instituciones educativas objeto de esta investigación se viene haciendo para promover la valoración de las diferencias con un enfoque que tiene su punto de partida en los derechos humanos.

A su turno, la visión de los estudiantes al referirse a las acciones desarrolladas para promover el respeto por las diferencias entre sus compañeros, se remite a comprender las tendencias religiosas o de estrato que se dan en un mismo salón de clase y reconocer que puede haber opiniones distintas, y por ello no pueden condenar o censurar al otro.

¡Bueno! Para mí, todas las personas son iguales. O sea, cuando yo veo como que hay ofensas que porque... ¡Ah!... no que usted que es evangélico, que usted no sé, que usted no sé qué más! Yo trato, como intentar dar a reflexionar a esa persona de que todos somos iguales y que no tiene que tratarla mal por ser de diferente religión, de diferente raza, por ser de diferente estrato o que llegue 
que porque es el chico popular del colegio tenemos que tratar a otro que tenga o sea su amistad no más. Entonces que porque es el popular del colegio entonces tienen que tratar mal a las personas. (E1EI)

De todos modos, pese a que los estudiantes comprenden la necesidad de respetar, y los docentes buscan estrategias para lograr que los jóvenes se apropien de tales competencias, en la práctica, se siguen dando casos en los que no se respetan las opiniones de sus compañeros: "Una estudiante (mujer) interviene, la mayoría guarda silencio y luego se ríe" (G202).

El contraste entre lo que se dice que se hace, lo que entienden los estudiantes y lo que sucede en el aula de clase, respecto de la promoción del respeto, permite establecer que, como lo señala Parsons (2007), "el enfoque de Derechos como política pública (vaya) orientado a que toda persona sin consideración de edad, color de piel, nacionalidad o convicción de Fe, sea sujeto de derechos, (y) conozca las figuras jurídicas creadas para la protección de los mismos..." (p. 15).

Sin embargo, pese a que se reconocen las intenciones, como afirman Chaux et al. (2004), hay un largo trecho aún por recorrer entre lo que se entiende por valoración de las diferencias, lo que se está intentando hacer para lograr la apropiación del respeto por esas diferencias entre los estudiantes y lo que real y efectivamente ocurre a diario en el ejercicio de la práctica pedagógica en el aula de clase.

\section{Consecuencias originadas por discriminación y exclusión}

Fenómenos como la depresión, la baja autoestima y el rechazo a la educación, son algunas de las consecuencias identificadas como parte de las acciones de discriminación que se dan en las instituciones educativas.

Depresión, se deprime. Él mismo empieza a rechazarse. Las veces que los demás lo rechazan. Él mismo se empieza a rechazar. Su autoestima queda abajo y pues yo creo que se encierra solo 
empieza a rechazarse a deprimirse a sí mismo. Tiene consecuencias graves. (E2EI)

Este tipo de sentimientos obedecen a lo que Bisquerra y Pérez (2007) señalan como la competencia emocional que consiste en "un constructo amplio que incluye diversos procesos y provoca una variedad de consecuencias". Tales procesos, cuando no están debidamente asimilados por quienes son blanco de irrespeto y de burla, generan los estados de ánimo como los narrados por el estudiante entrevistado.

En concordancia con estos resultados, los autores indican que "estas dimensiones se solapan con el concepto de inteligencia emocional" y argumentan -como lo define Goleman (1995)-, que es preciso dividirlas en cinco dominios: "autoconciencia emocional, manejo de las emociones, automotivación, empatía y habilidades sociales” (p. 66).

Como se evidencia en el relato del informante clave, tanto la autoconciencia emocional, como la empatía y sus habilidades sociales, han fallado, por lo que se producen los estados de ánimos narrados. Por su parte, los docentes se muestran preocupados por las manifestaciones de desmotivación que expresan algunos de sus alumnos cuando reciben voces de afecto de sus propios profesores.

En la sala de profesores: Dos docentes hablan de un estudiante de grado once. Dicen que pese a que se preocupan por él (tiene un dedo con sangre: uña encarnada) el estudiante, les responde (haciendo con la boca: pr, pr,pr y les dice, eso pa'que se preocupan por mí. Agregaron, que el mismo estudiante dice que cuando termine el colegio, no será "tan pendejo" de seguir estudiando. Profesoras explican que el alumno señala "que eso (estudiar) no sirve para nada”. (OG-JPC)

Desde la óptica de los docentes, quienes reflexionan sobre su práctica pedagógica en horas de descanso, es coherente asociar a este planteamiento de los educadores la propuesta de Saarni (citado en Bisquerra y Pérez, 2007) cuando considera que "la competencia emocional se relaciona con la demostración de autoeficacia al expresar emociones en las transacciones sociales" (p. 5). 
Saarni ve "la autoeficacia como la capacidad y las habilidades que tiene el individuo para lograr los objetivos deseados. Para que haya autoeficacia se requiere conocimiento de las propias emociones y capacidad para regularlas hacia los resultados deseados" (p. 67).

Así que Bisquerra y Pérez (2007) consideran que, desde esta perspectiva, toma relevancia la importancia del contexto: el espacio y el tiempo, dado que son condicionantes de la competencia emocional: "Todos podemos experimentar incompetencia emocional en un momento dado y en un espacio determinado, dado que no nos sentimos preparados para esa situación” (p. 67).

Esto es precisamente lo que sucede en el caso de algunos estudiantes quienes toman la decisión de reaccionar rechazando las expresiones de preocupación de sus docentes, demostrando que no tienen una competencia emocional que les permita automotivarse para seguir adelante: "Estudiantes fijando posición en debate de clase dicen que, en una eventual reinserción, los niños serían objeto de burla y ellos podrían tomar represalias porque vienen de ser violentos y actuarían violentamente" (G200).

De este modo, Martín, Berrocal y Brackett (2008) hacen referencia no solo a la necesidad de desarrollar competencias emocionales en los estudiantes, sino que consideran como fundamental incluir la formación de competencias emocionales en los profesionales del magisterio, en su proceso inicial de formación. Palomera et al. (2008) insisten en que "las competencias emocionales son competencias básicas que nos facilitan un adecuado ajuste personal, social, académico y laboral" (p. 448).

La postura de estos investigadores apunta a que es de prioritaria importancia que los docentes, como formadores de competencias emocionales, sean los primeros que deben estar adecuadamente empoderados de estas competencias para poder trasladarlas en las mismas proporciones a sus estudiantes. 



\section{Conclusiones}

\section{Convivencia y paz}

Es momento entonces de dar cuenta del primer objetivo de esta investigación, consistente en identificar las representaciones de docentes y estudiantes sobre competencias ciudadanas en el nivel de educación media de las instituciones educativas. Por lo tanto, se ha recorrido una ruta que permitió conocer las representaciones sociales que tanto docentes como estudiantes, en el marco de la práctica pedagógica, tenían de las competencias ciudadanas como parte de la labor de formación diaria a ejecutar en la escuela, entendida esta como el escenario propicio para tal actividad.

Así las cosas, un conflicto ha sido definido como las situaciones que partiendo de la diferencia de opiniones generan desencuentros producto de los intereses que cada actor en el conflicto puede tener. Existen, de acuerdo con la investigación, tres clases de conflicto: los verbales, los psicológicos y los de hecho, manifestados en agresiones físicas.

Como principal conclusión respecto a representaciones sociales de las competencias ciudadanas puede considerarse que los conflictos son inherentes al ser humano, hacen parte de la convivencia en unas comunidades educativas como estas, en las cuales se desarrolló el trabajo de indagación. Los actores en la investigación comprenden que 
los conflictos pueden ser incluso beneficiosos en la medida en que posibilitan opciones creativas para superarlos, por lo que es fundamentalmente necesario manejar unos conocimientos básicos de lo que significa el conflicto y su papel en los escenarios de paz y de convivencia de las instituciones.

Esto corrobora el planteamiento de Rodríguez (2005), quien dice que "los conocimientos entendidos como representaciones de la realidad (...) se construyen y acumulan según la formación y experiencia personal" (p. 70). Es evidente que en el caso de la idea de conflicto en estas comunidades educativas existe plena claridad sobre lo que es el conflicto, porque este se haya presente en las acciones cotidianas de la práctica pedagógica en las instituciones. Por tanto, el conocimiento sobre conflicto, para algunos informantes es por lo menos elemental, y en algunos otros alcanza a ser complejo, incluso por el mismo sentido común.

En las comunidades educativas en las cuales se llevó a cabo esta labor investigativa se tiene conciencia de que un ciudadano competente debe ser capaz de convivir con los demás de manera pacífica y constructiva, como lo reseña Enrique Chaux. En el marco de su práctica pedagógica, tanto docentes como estudiantes creen que esta convivencia no implica la armonía de ideas y no hablan de una total ausencia de conflictos. Las mismas comunidades educativas reconocen que la convivencia y la paz perfecta no son realistas, y entienden que ni siquiera es posible ni deseable.

Ahora, respecto al propósito de describir las prácticas pedagógicas para el desarrollo de las competencias ciudadanas en los niveles de décimo y undécimo grado de la institución educativa se concluye que en varias oportunidades los conflictos no son perceptibles a simple vista, sino que es necesario identificar actitudes de los alumnos en el aula de clase. Hay oportunidades en que al llegar al aula se perciben "ambientes pesados"; en otras palabras, cuando el docente ingresa al salón pueden identificarse posturas agresivas entre los mismos estudiantes cuando se propone trabajar en grupo, por ejemplo, o cuando los estudiantes responden alguna pregunta al docente, lo hacen en forma descortés y en ocasiones, incluso con tono de agresión verbal. 
En casos como estos, no existe explicación aparente de qué razones o causas han motivado tales comportamientos.

Es en escenarios como este un docente con un buen nivel de competencias ciudadanas identifica la situación conflictiva y sabe cómo proceder para buscar alternativas de solución. Aunque no todos, ni con la plena conciencia de una actuación intencionada, varios de los profesores hacen uso de sus competencias cognitivas y de razonamiento y de sus competencias de gestión de relaciones y capacidades de conocimiento y dominio personal para hallar el origen del problema y buscar alternativas de solución.

De tal manera que el ejercicio de la práctica pedagógica, independientemente de su área de dominio curricular por parte de los docentes, tiene que ver con la forma como ponen en práctica las estrategias para la resolución de conflictos en el aula. Un sector de la comunidad de práctica señala la imposición de autoridad como estrategia para dirimir un conflicto, seguido de charlas reflexivas que conducen a generar conciencia entre los estudiantes sobre la necesidad de aportar a la convivencia con actitudes positivas.

De esta forma de actuación, se colige, como lo señalan Bisquerra y Pérez (2007), que la competencia emocional constituye todo un amplio constructo que incluye procesos de diversa índole, lo que provoca un nutrido ramillete de consecuencias. Al revisar la práctica pedagógica de estas comunidades educativas se pudo establecer que no se da en todos los casos lo que Salovey y Sluyter (citados en Bisquerra y Pérez, 2007) llaman las cinco dimensiones básicas en las competencias emocionales, como cooperación, asertividad, responsabilidad, empatía y autocontrol.

Otra forma de desarrollar las competencias ciudadanas desde la práctica pedagógica es definida a través de la vía del diálogo, considerada como la mejor forma de redimir los conflictos que se dan al interior de las aulas, ya sea entre estudiantes o entre estudiantes y docentes. De lo que se trata, a juicio de las comunidades educativas, específicamente de los docentes, es de lograr procesos de reestructuración cognitiva, lo que posibilita cambiar pensamientos negativos y convertirlos en pensamientos positivos. En torno a estas formas de resolución de conflicto señaladas por los entrevistados, se evidencia lo 
anotado por Vilà (2003) al hacer referencia a los centros educativos escolares. Precisamente, dicho espacio representa un contexto diverso y multicultural, rico y complejo, privilegiado para promover unas relaciones humanas equitativas, lo que, contrapuesto a lo observado en las comunidades educativas focalizadas, se encuentra basado en una comunicación que, aunque no totalmente eficaz, sí facilita la convivencia entre sus miembros.

La práctica pedagógica en las instituciones educativas pasa igualmente por detener inmediatamente cualquier situación que pueda llegar a la agresión física, indagar por las razones que originaron el conflicto e intentar solucionarlo por la vía del diálogo. Esta forma de develación de los conflictos puede corresponde a la existencia de capacidades intelectuales, de los protagonistas de la práctica pedagógica que permiten realizar actividades cognitivas genéricas denominadas tareas no programadas o no rutinarias, las cuales son dependientes de la persona y que se dan en un entorno complejo, como lo describieran Kanungo y Misra (citados en Grau y Agut, 2001). Se convalida, asimismo, lo señalado por Grau y Agut cuando sostienen que "se centran en la importancia para atender situaciones diferentes no programadas de antemano, que están más dirigidas por la persona que por la tarea en sí” (p. 5).

Desde otra óptica, la manera más acertada de solucionar los conflictos está en la capacidad de sus compañeros para aconsejarlos cuando están pasando por situaciones difíciles. Se trata de acercarse a los estudiantes o a sus compañeros para escucharlos y reconocer los factores que pueden estar ocasionando las actitudes agresivas en el aula o fuera de ella. Tales acciones hacen evidente una competencia emocional relacionada con la demostración de autoeficacia al expresar emociones en las transacciones sociales. Parafraseando a Saarni (citado en Bisquerra y Pérez, 2007), se ve aquí la autoeficacia como la capacidad y las habilidades que tiene el individuo para lograr los objetivos deseados. Cuando se plantea la posibilidad de escuchar a sus compañeros y darles consejos, se está haciendo uso del conocimiento de las propias emociones y la capacidad para regularlas con miras a la consecución de unos resultados deseados.

Por su parte, los mismos estudiantes coinciden en que es mejor solucionar los conflictos buscando estrategias de entendimiento a través 
del diálogo. Ese diálogo, como lo anota Martínez Boom (1990), debe entenderse como una forma de pedagogía que ha alcanzado elaboraciones sistematizadas, ha desplegado teorías, elaborado nociones o simples objetos de discurso; discurso comprendido desde la noción de estrategias como asertividad, como capacidad de escuchar al otro y como habilidad para proponer alternativas de solución. Tal diálogo puede entonces, en el marco de la práctica pedagógica para el desarrollo de las competencias ciudadanas, configurarse como un saber independiente, que de todas maneras, como sostiene Vilà, significa el desarrollo de competencias comunicativas interculturales desde el marco escolar, lo cual debe para el caso de esta investigación ser la respuesta a muchos de los interrogantes que se plantean en el interior del aula.

Entonces, si el diálogo como estrategia de solución de conflictos, es una forma de práctica pedagógica, puede reconocerse esta como una positividad que reflexiona sobre un conjunto de objetos de saber: el saber pedagógico. Es decir, el saber dialogar constructiva y asertivamente para encontrar caminos de solución.

De este modo, Martínez Boom (2010) justifica que "entre estos saberes pedagógicos está la enseñanza, pero también el niño, la escuela, el conocimiento, etc.; serían estos, objetos del saber pedagógico, entendidos como una heterogeneidad de prácticas y de nociones que se dan en una sociedad a propósito de una práctica de saber" (p. 3).

A este punto, al desarrollar la labor de contrastación entre las representaciones sociales de las competencias ciudadanas y las prácticas pedagógicas, los hechos más significativos en el nivel de educación media de las instituciones educativas permiten evidenciar que mientras los docentes conciben un conflicto como aquello que genera una diversidad de criterios, y hace que de pronto se encuentren dos polos contrarios, los estudiantes señalan que un conflicto se caracterice por la multiplicidad de facetas que pueden ir desde lo verbal, pasando por las ideas, hasta llegar a las agresiones físicas.

Entre tanto, en la práctica pedagógica al interior del aula de clase, lo que se observó es que los docentes acceden a separar a los actores en conflicto de tal manera que los espacios físicos contribuyan a disminuir los roces, mientras que otras acciones posteriores, permitieron ver cómo los docentes reconvienen a sus estudiantes cuando los 
descubren hablando con sus compañeros, descuidando la atención al tema de la clase, o mientras otras compañeras exponen.

La triangulación de las ideas de conflicto como eje articulador de la competencia de convivencia y paz es concebida entonces como un factor que se genera en la diversidad de criterios, según los docentes. Mientras que para los estudiantes el conflicto, si bien no riñe con la definición de los docentes, es complementado en tanto se conciben varias maneras de conflicto, entre ellos el verbal, el físico y el de ideas, en la aplicación de tales ideas, los docentes siguen siendo tradicionales al intentar resolver los conflictos con el fin de mantener una convivencia "manejable" en el aula, separando a los actores del conflicto o llamando la atención de quienes hacen parte de un desacuerdo.

Finalmente, en este apartado, luego de todo este proceso de investigación que partió desde la identificación de una situación problemática que invitó a indagar por el estado del desarrollo de las competencias ciudadanas en las prácticas pedagógicas de los docentes y estudiantes de nivel de educación media de las instituciones educativas, partiendo de las representaciones sociales que los miembros de esas comunidades tenían de las propias competencias, se puede afirmar que el grado de desarrollo es incipiente.

Si bien es cierto que existe un factor importante en la medida en que es de norma y de ética fomentar el desarrollo de las competencias ciudadanas transversalmente a todas las áreas del currículo, y acertado, en tanto las representaciones sociales que tienen de las competencias ciudadanas, los actores de esta investigación no distan mucho de las posiciones teóricas de lo que deben ser las competencias ciudadanas en sus tres elementos: paz y convivencia, participación y responsabilidad democrática, y pluralidad, identidad y valoración de las diferencias. En el ejercicio de la práctica pedagógica existen divergencias significativas desde la perspectiva de cada uno de sus actores.

Los docentes tienen opiniones en algunos casos opuestas en cuanto a la forma en que deben formular acciones para promover la convivencia y la paz, mientras que los estudiantes sienten que, en ocasiones, son los mismos educadores quienes, con sus actitudes en el aula, promueven los conflictos. Pero por su parte, los estudiantes, con comportamientos displicentes, en ocasiones contribuyen a la alteración del 
estado normal de la convivencia por causas diversas que van desde los apodos a sus compañeros, hasta el mal trato verbal entre ellos.

\section{Participación y responsabilidad democrática}

El primer objetivo, de identificación de las representaciones sociales respecto a la participación y la responsabilidad democrática, permite concluir que estas se conciben como el otorgamiento de los espacios a las comunidades educativas para que puedan cumplir con su rol y parte del poder que tiene la misma comunidad para tomar decisiones. Cuando se hace referencia a dar espacios a toda la comunidad, se está identificando la pretensión del Ministerio de Educación Nacional, al considerar la participación y la responsabilidad democrática como un espacio para la toma de decisiones en diversos contextos, teniendo en cuenta que dichas decisiones deben respetar, tanto los derechos fundamentales de los individuos, como los acuerdos, las normas, las leyes y la Constitución que rigen la vida en comunidad (MEN, 2004, p. 12).

No obstante, la participación en algunos sectores de las comunidades de esta investigación, se concibe como una metodología de acción y participación. Se entiende la metodología como la actuación de las personas a partir de normas fijadas previamente por las instituciones con base en una escala de valores, normas y preceptos dispuestos previamente. Por tanto, la participación queda circunscrita a actuar a partir de tales lineamientos. En el marco de tal metodología, todos son iguales, pero están restringidos solo a cumplir con sus responsabilidades y hacer efectivos sus derechos, pero sin tener mayor opción de disentir.

Respecto a esta visión, se observa una divergencia, en la medida en que Chaux et al. (2004) señalan que "una sociedad que quiere ser realmente democrática requiere de la participación activa y crítica de todos". En su referencia al tema, agregan que "esto implica que todos sus miembros deben poder estar involucrados en la construcción de acuerdos y en la toma de decisiones tanto en el nivel macro como en el nivel micro" (p. 19). 
Al describir las prácticas pedagógicas en este segundo grupo de competencias, se estableció que, aunque existe conciencia de la importancia de la participación en los diferentes escenarios de la vida escolar, y se pretende generar una cultura de responsabilidad democrática, al interior de las instituciones, en la práctica, no se ha asumido realmente el rol que deben desempeñar los estudiantes de manera plena, según lo señalan los docentes entrevistados.

Aquí se evidencia, en palabras de Geilfus (citado en Dueñas y García, 2011), que "participar debe significar tomar parte en las decisiones y las responsabilidades desde el sitio en el que se está, desde la función que se ocupa, para ello es necesario el diálogo y por supuesto la organización” (p. 7). Sin embargo, aunque los espacios de participación se dan, los estudiantes no los asumen con la seriedad que lo deberían hacer. Es decir, que la participación ciudadana considerada como el espacio ideal para fortalecer la democracia y formar a los futuros ciudadanos participativos y con voluntad para hacer propuestas en bien de su comunidad, para el caso del establecimiento educativo es vista por los estudiantes como una mera actividad trivial, y falta de sentido y significado.

Se pudo identificar que en el grupo de competencias que involucran la participación y la responsabilidad democrática no ha sido posible avanzar satisfactoriamente, por lo que actividades como la elección del personero, o los organismos de control y de gobierno escolar, se cumplen como un proceso meramente mecánico, para elegir unos representantes, pero que en la práctica no operan. Visto el fomento de la participación en términos de competencia democrática responsable como una práctica pedagógica, desde los aportes de Zuluaga (citado en Martínez Boom, 1990), cuando explica que entendiendo que el saber permite explorar desde las relaciones de la práctica pedagógica con la educación, la vida cotidiana de la escuela y el entorno sociocultural que lo rodea, es demostrable que no existe una visión clara ni una perspectiva definida de lo que debe ser una comunidad educativa con valores democráticos ni participativos lo suficientemente desarrollados ni interiorizados.

Las razones que han llevado a que los estudiantes no participen con una conciencia plenamente responsablemente en las decisiones democráticas al interior de las instituciones, están ligadas a factores 
como la falta de motivación. En este sentido, los estudiantes reconocen que existen serias falencias a la hora de tomar decisiones, puesto que cuando se dan los espacios para elegir, no siempre se hace con toda la responsabilidad. Esto implica, en palabras de Dueñas y García (2011), que para lograr esto debe tener lugar una transformación estructural, lo que implica establecer programas de acción a partir de asumirlas, tales como que la participación debe ser una preocupación de la educación escolar. Lo confirmado en la comunidad de práctica focalizada es que la participación aún está en ciernes para ser considerada una construcción social fuerte y robusta. Además, se requiere un proceso de formación de cultura de participación de aprendizaje, que debe ser considerada como una competencia (transversal) dentro de los objetivos de la educación basada en competencias.

Al contrastar lo señalado por estudiantes y docentes con las clases observadas, se registró el desarrollo de un debate sobre diferentes temas de interés, uno de ellos, el proceso de paz que se lleva a cabo en la actualidad en La Habana (Cuba). Mientras algunos estudiantes prestaban atención, otro tanto tomaban actitudes de desinterés y apatía a la temática.

En síntesis, en el ámbito de la participación y la responsabilidad democrática, los docentes tienen claro que es necesario promover espacios en los que el estudiante pueda tomar parte con el fin de ejercer una democracia responsable. No obstante, entre los estudiantes existe desinterés en vincularse a este tipo de actividades en tanto sienten que, pese a que eligen a sus voceros, estos no cumplen cabalmente lo que se comprometen a desarrollar. Adicionalmente, reconocen que muchas veces no votan por las mejores ideas, sino por quien puede significar un beneficio personal al ser elegido a nivel del aula o de la institución.

\section{Identidad, pluralidad y valoración de las diferencias}

En este apartado se logra identificar que sobre identidad, pluralidad y valoración de las diferencias existe efectivamente una representación social en una modalidad particular del conocimiento que se tiene sobre 
este grupo de competencias. En efecto, tales representaciones buscan construir una especie de teoría explicativa y evaluativa del entorno a partir del discurso ideológico de las competencias ciudadanas del que se tiene una interpretación al interior de las instituciones educativas donde se llevó a cabo esta investigación y que pretende permear desde los docentes hasta los estudiantes. Para buscar lograr este cometido, sin poderlo justificar teóricamente, los docentes comprenden este ejercicio como una práctica discursiva que les sirve como un aparato instrumental de la ideología, en este caso de una adecuada valoración de las diferencias que implican reconocer la identidad, en la pluralidad y en la diversidad, como un sistema significante que elabora sus propias normas a partir de las diferentes disciplinas del conocimiento y construye una serie de instrumentos o reglas para incidir en los discursos no pedagógicos.

Al hacer referencia a las representaciones de identidad que tienen los docentes, se mencionan varias características, entre ellas, el sentirse identificado con el lugar de donde se es oriundo, o con relación a la personalidad. Para los actores de esta investigación, como lo proponen Chaux et al. (2004), la identidad es considerada como la visión que cada persona tiene de sí, no solo como individuos, sino también como miembros de grupos sociales o, inclusive, de naciones, por lo que un ciudadano competente no solamente reconoce sus múltiples identidades, sino que reconoce y valora las de los demás.

Por su parte, los estudiantes asumen la identidad mostrándose ante sus compañeros y profesores a partir de sus actuaciones y desempeños: se puede interpretar desde Bernal (2004) como la "identidad personal" comprendida como un proceso eminentemente dinámico porque en el curso de la vida misma los elementos configuradores de la identidad pueden modificarse. Bernal considera que en todo este proceso se produce un movimiento hacia la segregación, hacia la independencia, hacia la individuación, que resulta básico para llegar a construir la identidad personal.

Se concluye entonces que la práctica pedagógica, pese a que busca el desarrollo de las competencias de identidad y pluralidad como un escenario en el que se pueden incluso trascender las fronteras del aula para generar efectos transformacionales verdaderamente eficaces, 
necesita poner en práctica estrategias metodológicas adicionales. En desarrollo de tales prácticas, si los sujetos que aprenden, los estudiantes, adquieren los elementos de juicio para desempeñarse exitosamente en la vida no solo desde los académicos y lo científico, sino desde sus habilidades para interactuar socialmente, lo puede generar un ejercicio que vaya mucho más allá de comprender las importancias de valorar la diferencia, y llegar a poner en práctica dicha valoración.

Pero, además, para la comunidad de práctica focalizada como lo señala Fayad (2010), la pedagogía es considerada una práctica discursiva que se comprende, por tanto, como un aparato instrumental de la ideología y como un sistema significante que elabora sus propias normas a partir de otras disciplinas, mientras que construye una serie de instrumentos o reglas para incidir en los discursos no pedagógicos. Tales discursos van direccionados a lograr la interiorización de la valoración de las diferencias reconociendo la identidad y aceptando la pluralidad en el seno de las instituciones educativas.

Bajo estos presupuestos teóricos, se concluye que la forma como en el desarrollo de la práctica pedagógica los docentes promueven, entre otros aspectos, la inclusión, permite ver que existe una política institucional para ello, pero a la hora de llevarla a la práctica, muchas veces no se ejecuta. Entre tanto, se asocia la inclusión con el manejo inadecuado de los comportamientos disciplinarios mientras que se considera que darles libertad a los jóvenes genera demasiados conflictos.

Estas afirmaciones se asimilan a los planteamientos de Engelken (2005), quien refiere la capacidad explicativa que la identidad tiene sobre ideas y comportamiento y que remite al problema de la (auto) conciencia como variable independiente. Esto puede interpretarse como las ideas que una persona puede tener sobre inclusión, pero que difieren en la práctica por no ajustarse a su propio modo de actuar.

Adicionalmente, aunque se entiende la necesidad de facilitar los espacios para que todos puedan participar y desarrollarse, cuando se proponen temas álgidos, como por ejemplo un eventual posconflicto en Colombia, un significativo sector de los estudiantes se muestra escéptico e incluso rechaza la posibilidad de otorgar derechos a quienes han sido parte del conflicto. García y Mieles (2010) en su trabajo reflexionan acerca de cómo las sociedades en algunas regiones y ciertas 
poblaciones se han visto forzadas a abandonar sus sitios de origen y cambiar de residencia, viéndose obligados a adaptarse a otras costumbres e iniciar nuevos procesos de socialización trayendo problemas en la construcción de identidad en especial de los niños y niñas, los cuales generan cambios de rol de las familias en la crianza de los hijos.

En esta misma línea, Chaux et al. (2004) evidencian que es necesario trabajar más en el desarrollo de la identificación de las emociones de los demás, entendida como la capacidad para identificar lo que pueden estar sintiendo otras personas tanto por medio de sus expresiones verbales y no verbales, como teniendo en cuenta la situación en la que se encuentran.

Pese a que existen ejemplos relevantes que sirven como muestra de inclusión y de respeto a las diferencias al interior de las instituciones, dado que hay varios estudiantes con limitaciones físicas que reciben apoyo tanto de sus profesores, como de sus compañeros, se presentan casos evidentes de discriminación que, si bien no es sistemática, sí reflejan debilidad en el proceso de desarrollo de las competencias ciudadanas. Estas formas de actuar muestran, según Perrenoud (citado en Rodríguez, 2005), una falencia en

la capacidad para actuar eficazmente en una situación definida, haciendo uso de los conocimientos, pero sin limitarse sólo a ellos". Según tal consideración, "para hacer frente a una situación de manera óptima, en general se necesita hacer uso y asociar varios recursos cognitivos complementarios, tales como los conocimientos. (p. 70)

Esto significa que cuando se toman decisiones sobre situaciones que comprometen la participación de los estudiantes no se pondera la necesidad de prevenir que ellos puedan ser objeto de discriminación, así no se tenga la intención directa de hacerlo.

Por su parte, entre los mismos estudiantes se reconocen actuaciones discriminatorias que buscan generalmente ridiculizar a un determinado estudiante frente a sus pares. La utilización de apodos es una de las principales formas de identificación de casos de discriminación. En 
este caso, contrario a lo considerado por Walzer, quien plantea que es necesario comprender el escenario escolar como una institución social, que forma a los niños, niñas, adolescentes y jóvenes para que tomen decisiones informadas, autónomas, responsables, placenteras y saludables que enriquezcan sus proyectos de vida, en términos prácticos, las presiones de sus compañeros no permiten que tales decisiones se puedan tomar bajo tales criterios en formal cabal, en las instituciones.

En el otro elemento, concerniente a la representación que los docentes tienen de pluralidad en el marco de las competencias ciudadanas, existe la idea de que la pluralidad involucra la inclusión como posibilidad de convivencia en una misma comunidad. Desde la postura de Navarro (2008), cuando menciona que una comunicación para la inserción, la interacción y la convivencia de los sujetos en un lugar lleno de iguales-plurales-distintos, posibilita la realización de la condición humana, propiamente comunicativa, y como expresión de pluralidad. Para Navarro, no es otra cosa que "vivir como ser distinto y único entre iguales" (p. 340).

Sobre la representación de pluralidad, es definida como diversidad en una misma comunidad, en este caso escolar. Esta concepción se relaciona en forma directa con la forma de pensar de Bartolomé (2002) cuando manifiesta que el lugar y el momento hacen que el ciudadano en formación se identifique con su comunidad, el Estado o la sociedad general, teniendo en cuenta el multiculturalismo, la diversidad y el surgimiento constante de ideas (p. 131).

La representación referida a la valoración de las diferencias, destaca la diversidad de personalidades, formas de pensamiento y de actuación que tienen los estudiantes. Hay casos desde estudiantes muy extrovertidos, hasta jóvenes que prefieren mantenerse al margen del grupo. Sin embargo, todos conviven en una relativa tranquilidad. Lo aquí expresado se asume, según Walzer (1996), dado que en la actualidad la homogeneidad es un factor inexistente. Por ello el escenario de la escuela como institución se constituye en el espacio oportuno en el que se construyen las identidades tanto individuales como colectivas. Pero, además, la valoración de las diferencias se concibe con la necesidad de que todos los estudiantes puedan destacarse por sus 
capacidades, talentos y habilidades, sin que, por sus dificultades, sean excluidos de participar en lo que a ellos les gusta.

Lo expuesto se puede resumir en la posición de Chaux et al. (2004) cuando advierten que la pluralidad y la valoración de las diferencias es en últimas el reconocimiento, el respeto y la valoración de las múltiples identidades propias y las de los demás, por lo que la pluralidad y la valoración de las diferencias no pueden llevar a que se tolere a quienes vulneran derechos fundamentales.

En cuanto a la forma como se refleja en las prácticas pedagógicas el trabajo para desarrollar la competencia de valoración de las diferencias, existe una marcada intencionalidad para manifestarse comprometidos en este sentido. Por ello, programaron actividades de formación para socializar con los estudiantes. En este sentido, la justificación de Lahera (2004) cuando manifiesta que es posible definir una política pública como aquellas acciones dirigidas a mejorar la administración de un tópico nacional y que estas acciones deben ser orientadas por el Estado a través de las instituciones públicas y, en el mejor de los casos, deben ser apoyadas por la comunidad beneficiaria (p. 5), se ajustan oportunamente en la labor que en las instituciones educativas objeto de esta investigación se viene haciendo para promover la valoración de las diferencias con un enfoque que tiene su punto de partida en los derechos humanos.

Pero, además, al describir las prácticas pedagógicas en el componente de valoración de las diferencias, se observa cómo es posible comprender las tendencias religiosas o de estrato social que se dan en un mismo salón de clase y reconocer que puede haber opiniones distintas, y por ello no se puede condenar o censurar al otro. De todos modos, pese a que los estudiantes comprenden la necesidad de respetar y los docentes buscan estrategias para lograr que los jóvenes se apropien de tales competencias, en la práctica se siguen dando casos en los que no se respetan las opiniones de sus compañeros.

Lo que se pudo verificar en las observaciones en el aula de clase es que hay acciones en las que no se le permite a un estudiante participar, o se le critica por cometer un error. Al triangular la información obtenida desde diferentes fuentes (docentes, estudiantes y observación no participante), se logró evidenciar que al interior de las instituciones 
existe una concepción acertada de lo que se considera teóricamente como identidad, pluralidad y valoración de las diferencias. En el ejercicio diario de la labor pedagógica se intenta desarrollar tales competencias y se ponen en práctica varias estrategias, pero en el desarrollo mismo de la acción cotidiana resta mucho trabajo por hacer, dado que los estudiantes, incluso algunos docentes, no validan las representaciones que tienen de tal grupo de competencias.

En síntesis, en el escenario de la identidad, la pluralidad y la valoración de las diferencias, existe de igual manera una idea significativamente clara de qué son este grupo de competencias y cómo deben promoverse. Las instituciones han dado muestras importantes de inclusión, de valoración de las diferencias y de pluralidad, en la medida en que facilita la formación en sus aulas de niñas, niños y jóvenes que hacen parte de la población con necesidades educativas especiales. Sin embargo, en el desarrollo cotidiano de la práctica pedagógica, se dan casos de discriminación y exclusión que, si bien no son sistemáticos, ni reiterativos, para ser considerados graves, sí evidencian la necesidad de fortalecer acciones que permitan entre estudiantes y profesores una mejor comprensión y desde luego una mejor acción en la valoración de las diferencias con la población, particularmente que no hace parte de este grupo de estudiantes con limitaciones.

\section{Impactos del proyecto}

1. Empoderar nuevos conceptos de ciudadanía y de lo público como conceptos íntimamente vinculados en la formación para la democracia.

2. Concebir el espacio público como el ideal democrático (diálogo, tolerancia, pluralismo político y religioso, libertad e igualdad política y social).

3. Definir el espacio público como el escenario donde se dan las relaciones y la interacción de los actores sociales. Por ello, el proyecto aporta que el estudiar la democracia es indagar sobre el tipo y dinámica de estas relaciones. Es indagar, asimismo, 
sobre nuevas interacciones sociales y su dinámica en el espacio público y democrático.

4. El proyecto considera que un ciudadano tiene derechos democráticos y exigencias de justicia; contemporáneamente, la ciudadanía ha tomado un perfil sustancial en el nivel gubernamental, como es la promoción de la ciudadanía responsable -ciudadanía activa- en la toma de las decisiones públicas.

5. El ayudar a superar la concepción del papel de receptores de derechos -ciudadanía pasiva- que representa un problema para los jóvenes, pues el acceso a los derechos sociales es cada vez más difícil por la tendencia de los gobiernos para implementar políticas “compensatorias” (coyunturales) sustituyéndolas por políticas sociales "niveladoras". Es una tendencia propia de sistemas como el nuestro, en el que prevalece "atacar" los conflictos tangencialmente y de inmediato para evitar problemas propios de gobernabilidades no propiamente legítimas.

6. Finalmente, el gran aporte es producir una propuesta en "competencias ciudadanas" como apuesta desde el posacuerdo en Colombia. 


\section{Referencias}

Agut, S., y Grau, R. (2001). Una aproximación psicosocial al estudio de las competencias. Proyecto social: Revista de Relaciones Laborales, (9), 13-24.

Alemany, I., Ortiz, M., Rojas, G. y Herrera, L. (2012). Convivencia escolar: percepciones de los profesores de Primaria y Secundaria de la Ciudad Autónoma de Melilla. Revista Iberoamericana de Educación, 1(60), 1-12.

Álvarez-García, D., Cerezo, R., González-Pienda, J., Núñez, J., Rodríguez, C., Álvarez, L., y González-Castro, P. (2010). Violencia en los centros educativos y fracaso académico. Revista Iberoamericana de Psicología y Salud, (1), 139-153. Recuperado de http://www.redalyc.org/articulo. oa? id=245116406002

Alzate, R., Fernández, I. y Merino, C. (2013). Desarrollo de la cultura de la paz y la convivencia en el ámbito municipal: La mediación comunitaria. Revista Política y Sociedad, 50(1), 179-194. Recuperado de http://revistas.ucm.es/index.php/POSO/ article/view/39350.

Arellano, N. (2007). La violencia escolar y la prevención del conflicto. Revista Orbis, 3 (7), 23-35. Recuperado de http://scholar.google.com.co/scholar?start $=30 \& q=$ Convivencia $+\mathrm{y}+$ paz\&hl=es\&as_sdt $=0,5$

Arenal, C. (1989). La noción de paz y la educación para la paz. AA. VV: Seminário sobre formación de monitores de educación para la paz. Madrid: Cruz Roja Española. 
Azcune, E. (2013). La importancia de la resolución pacífica de conflictos cotidianos en el aula. Recuperado de https://82.223.209.184/xmlui/bitstream/ handle/123456789/1223/2012_11_09_TFG_ESTUDIO_DEL_TRABAJO.pdf?sequence $=1$

Aznar, I., Cáceres. M. y Hinojo, F. (2008). Formación integral: educar para la convivencia y la paz. Revista Iberoamericana de Educación, 5(46), 1-16. Recuperado de http://www.rieoei.org/deloslectores/2466Caceres.pdf

Bañez, T. (1999). Participación ciudadana, sociedad civil y juventud. Revistas Acciones e Investigaciones Sociales, 1(9), 101-124. Recuperado de http://dialnet.unirioja.es/ servlet/busquedadoc?t=participaci\% $\mathrm{C} 3 \% \mathrm{~B} 3 \mathrm{n} \& \mathrm{db}=1 \& \mathrm{td}=$ todo

Barragán, D., Gamboa, A. y Urbina, J. (2012). La práctica pedagógica: pensar más allá de las técnicas. Bogotá: Ecoe.

Bartolomé, M. (2002). Identidad y ciudadanía: un reto a la educación intercultural. Madrid: Narcea.

Benítez, L. (2009) Educación y construcción de culturas de paz en la escuela: de la práctica a la teoría. Pensamiento Jurídico, (26). ¿La Paz es Posible?: Aproximaciones Interdisciplinarias; 143-160 2357-6170 0122-1108.

Bernal, A. (2004). La construcción de la identidad personal como proyecto de educación moral. Supuestos teóricos y delimitación de competencias., Teoría de la Educación. Revista Interuniversitaria 1(15), 129-160. Recuperado de http://campus.usal.es/ revistas_trabajo/index.php/11303743/ article/viewFile/3033/3066

Bisquerra, R. y Pérez Escoda, N. (2007). Las competencias emocionales. Educación XXI: Revista de la Facultad de Educación, 2(10), 61-82.

Bromme, R. (1988). Conocimientos profesionales de los profesores. Enseñanza de las Ciencias, 6(1), 19-29. Recuperado de: http://www.inet.edu.ar/ programas/formacion_docente/biblioteca/formacion_docente/bromme conocimientos_profesionales_profesores.pdf

Buarque, M. (2012). La participación de los consejos escolares para la gestión democrática de la escuela pública. Revista Educar, 48(2), 285-298. Recuperado de http://ddd.uab.cat/pub/educar/educar_a2012m7-12v48n2/ educar_a2012m7-12v48n2p285.pdf

Caballero, M. (2010). Convivencia escolar un estudio sobre buenas prácticas. Revista de Paz y Conflictos, 1(3), 154-169. Recuperado de: http://www. ugr.es/ revpaz/tesinas/rpc_n3_2010_dea5.pdf. 
Canal, A., Mosquera, J. y Flórez, C. (2012). Estrategias para la mitigación de la violencia homicida en la fronteriza ciudad de Cúcuta. Revista Luna Azul, 1(38), 297-317.

Centro Nacional de Memoria Histórica (Colombia). Área de Memoria Histórica. (2013). ¡Basta ya! Colombia: Memorias de guerra y dignidad. Centro Nacional de Memoria Histórica. Bogotá.

Chaux, E., Lleras J. y Velásquez, A. (2004). Competencias ciudadanas: de los estándares al aula. Una propuesta de integración a las áreas académicas. Bogotá: MEN - Ediciones Uniandes.

Chaux, E. (2005). Estándares básicos de competencias ciudadanas: estructura $y$ proceso de construcción. Taller Internacional de Formación en Competencias Ciudadanas, Ministerio de Educación Nacional. Bogotá: OEA, Oficina de Educación, Ciencia y Tecnología.

Clavijo, S. (2009). Formación para la profesionalización. Mutatis Mutandis, 2(1), 67-72.

Coronado, J. (2008a). Artículo: mitos del aprendizaje por competencias. Recuperado de http://ined21.com/mitos-del-aprendizaje-por-competencias/

Coronado, M. (2008b). Competencias sociales y convivencia. Buenos Aires: Novedades Educativas.

De Cerio, Z. (1998). Bases de una educación para la paz y la convivencia. Recuperado de http://www.comisionunesco.mec.gub.uy/innovaportal/ file/29930/1/bases_de_una_ed_para_la_paz_y_la_convivencia.pdf

Deleuze, G. y Guattari, F. (1999). ¿Qué es la filosofía? Barcelona: Anagrama.

Díaz-Aguado, M. (2001). Convivencia escolar \& prevención de la violencia. Recuperado de http://eoepsabi.educa.aragon.es/descargas/G_Recursos_ orientacion/g_2_accion_tutorial/g_2_3.materiales_varios/01.Prevencion_violencia.pdf

Díaz-Bravo, L., Torruco-García, U., Martínez-Hernández, M., y Varela-Ruiz, M. (2013). La entrevista, recurso flexible y dinámico. Investigación en educación médica, 2(7), 162-167. Recuperado de http://riem.facmed. unam.mx/node/47

Díaz de Cerio, J. (1998). Bases de una educación para la paz y la convivencia. Gobierno de Navarra, Departamento de Educación y Cultura. Pamplona.

Dodge, K., Bates, J. y Pettit, G. (1990). Mechanisms in the cycle of violence. Science, 250. 
Dopico, E. (2011). Conflicto y convivencia en los entornos escolares. Cuadernos de Educación y Desarrollo, 3(26), 1-6. Recuperado de http://www. eumed. net/rev/ced/26/edr.htm

Dueñas, L. y García, J. (2011). El papel de la educación escolar en la construcción de cultura de participación y de ciudadanía democrática. Revista Razón y Palabra, 1(77), 1-16. Recuperado de http://www.razonypalabra. org.mx/varia/77\%203a\%20parte/ 52_DuenasGarcia_V77.pdf

Eckhardt, W. (1986). The Task of Peace Research. A Future Oriented Endeavour. Bulletin of Peace Proposals.

Engelken, M. (2005). La metáfora de lo uno-múltiple: una (re) conceptuación dialógica de la identidad personal (una crítica al reduccionismo postmodernista). Athenea Digital: Revista de Pensamiento e Investigación Social, 1(7), 114-132.

Escudero, J. (2006). Compartir propósitos y responsabilidades para una mejora democrática de la educación. Revista Educación, 2(339), 19-42. Recuperado de http://dialnet.unirioja.es/servlet/busquedadoc?t=Responsabilidad+democr \%C3\%A1tica\&db=1\&td=todo

Fayad, J. (2009). Adquirir el don de la pedagogía. Significa defender la profesión del docente. En Boom, A. y Álvarez, A. (2009). Figuras contemporáneas del maestro en América Latina. 30 años del grupo de historia de la práctica pedagógica (Colección: pedagogía e historia). Bogotá: Editorial El Magisterio.

Fisas, V. (1998). Cultura de paz y gestión de conflictos. Barcelona: Icaria - Unesco.

Freire, P. (1993). Pedagogía de la esperanza: un reencuentro con la pedagogía del oprimido. Río de Janeiro: Siglo XXI.

Fuentes-Navarro, R. (2008). La comunicación desde una perspectiva sociocultural: acercamientos y provocaciones 1997-2007. Guadalajara: Iteso.

Galtung, J. (1985). Sobre la paz. Barcelona: Fontamara.

García, A. (1998). Un aula pacífica para una cultura de paz. Revista de Escuelas Normales, 1(1), 1-16. Recuperado de file:///Users/user/Desktop/Revista $\% 20$ digital/VOLUMEN\% $201 \% 20(1) \% 20$ DIGITAL/articulo $\% 20$ garcia $\% 20$ correa.webarchive

García-Hierro, M. y Cubo, S. (2009). Convivencia escolar en Secundaria: aplicación de un modelo de mejora del clima social. Revista Electrónica Interuniversitaria de Formación del Profesorado, 12(1), 51-62. Recuperado de http://www.redalyc.org/articulo.oa?id=217015332004. 
García, M. y Mieles, M. (2010). Apuntes sobre socialización infantil y construcción de identidad en ambientes multiculturales. Revista Latinoamericana de Ciencias Sociales, 8(2), 809-819.

García, M. (2012). La autorregulación académica como variable explicativa de los procesos de aprendizaje universitario. Profesorado. Revista de $\mathrm{Cu}$ rrículum y Formación de Profesorado, 203-221. Recuperado de http:// www.redalyc.org/pdf/567/56724377012.pdf

Gijón, M. y Puig, J. (2010). Encuentros y convivencia escolar. Educação. Revista do Centro de Educação, 35(3), 367-379.

Goleman, D. (1995). Inteligencia emocional. Barcelona: Kairós.

Gómez, L. (2009). Cultura de paz en las instituciones de educación superior: un imaginario para la convivencia humana. Laurus, 15(29).

Gonczi, A., y Athanasou, J. (1996). Instrumentación de la educación basada en competencias. En A. Argüelles (comp.), Competencia laboral y educación basada en normas de competencia (pp. 272-273). México: Limusa/ SEP/CNCCL/CONALEP.

Grabe, V. (2006). Pacicultores en la Vida. Bogotá: Obserpaz.

Herrera, M. C. (2008). Políticas públicas en educación ciudadana en Colombia y América Latina: La arena de lucha del campo intelectual en la historia reciente. Historia de la educación-anuario, 9, 0-0.

Hicks, D. (1999). Educación para la paz. Madrid: Morata.

Ilvento, M. (2005). Las representaciones sobre el campo profeisonal en ciencias de la educación. La incidencia de las prácticas pre-profesionales. Universidad Nacional de Salta. Recuperado de http:// nportal0.urv.cat:18080/fourrepo/rest/digitalobjects/DS?objectId= TDX:675\&datastreamId=Memoria\&mime=application $/ \mathrm{pdf}$

Jares, X. (1999a). La educación para la paz en el umbral del nuevo siglo: retos y necesidades. La Coruña: Universidad de La Coruña.

Jares, X. R. (1999b). Educación para la paz: su teoría y su práctica. Editorial Popular.

Jares, X. (2001). Educación y conflicto: guía de educación para la convivencia. Madrid: Editorial Popular.

Jares, X. (2002). Aprender a convivir. Revista interuniversitaria de formación del profesorado, (44), 79-92. Recuperado de https://dialnet.unirioja.es/ descarga/articulo/249633.pdf 
Kanung, R. y Misra, S. (1992). Managerial resorcefulness: A reconceptualization of management skills. Human Relations, 45(12), 1311-1332.

Katterman, D. y Aramayo, F. (2011). Sistematización y aprendizajes. Gestión Constructiva de conflictos sociales en el ámbito de la gestión pública. Monitoreo, análisis y transformación de conflictos en el nivel central de Órgano Ejecutivo. La Paz: GIZ-PADEP.

Krauskopf, D. (2000). Dimensiones críticas en la participación social de las juventudes. La participación social y politica de los jóvenes en el horizonte del nuevo siglo, 119-134. Recuperado de http://bibliotecavirtual. clacso.org.ar/ar/libros/cyg/juventud/krauskopf.pdf

Lahera, E. (2004). Política y políticas públicas (vol. 95). Santiago de Chile: United Nations Publications.

Lederach, J. (1984). Educación para la paz. Objetivo Escolar. Barcelona: Fontamara.

Lederach, J. (2000). El abecé de la paz y los conflictos: educación para la paz. Madrid: Catarata.

Lederach, J. (2008). La imaginación moral: el arte de construir la paz. Bogotá: Norma.

Mariñez, F. (2009). La participación ciudadana en los programas de formación cívica y ética de la educación secundaria. México: Fondo Editorial de Nuevo León.

Martín, R., Berrocal, P. y Brackett, A. (2008). La inteligencia emocional como una competencia básica en la formación inicial de los docentes: algunas evidencias. Electronic Journal of Research in Educational Psychology, 6(15), 437-454. Recuperado de http://www.investigacion-psicopedagogica.org/revista/articulos/15/ espannol/Art_15_276.pdf

Martínez Boom, A. (1990). Una mirada arqueológica a la pedagogía. Revista pedagogía y saberes, (1). Recuperado de http:/www.pedagogica.edu.co/ storage/ps/articulos/pedysab01_04arti.pdf

Martínez Boom, A. (2010). Alteraciones y diluciones en la educación de hoy. En Frigerio, G. y Diker, G. (2010). Educar, saberes alterados. Del estante editorial. Buenos Aires.

Martínez, M. (2006). Ciencia y arte en la metodología cualitativa. México: Editorial Trillas.

M.E.C. (1992). Prólogo. Temas transversales (Cajas rojas). Madrid: MEC. 
Mesa, M. (2001). Educación para la paz en el nuevo milenio. En Pureza, J. (Org.), Para uma cultura da paz. Coimbra, Portugal: Quarteto editora.

Ministerio de Educación Nacional. (2004). Cartilla guía 6: Formar para la ciudadanía... ¡sí es posible! Lo que necesitamos saber y saber hacer. Bogotá: El Ministerio.

Ministerio de Educación de Brasil. (2005). Programa ética y ciudadanía: construyendo valores en la escuela y en la sociedad. Brasilia: Ministerio de Educación. Recuperado de http://www.oest.oas.org/colombia/presentaciones/Día\%201/Presentación\%20Brasil.ppt

Mockus, A. (2002). La educación para aprender a vivir juntos: convivencia como armonización de ley, moral y cultura. Perspectivas, XXXII(1), 19-37.

Montoro, C. (2008). La convivencia escolar en nuestros centros educativos: recursos para trabajar la convivencia. Caleidoscopio. Revista de Contenidos Educativos del CEP de Jaén, 1(1), 101-110. Recuperado de http:// dialnet.unirioja.es/servlet/articulo? codigo $=2745872$

Mora, M. (2002). La teoría de las representaciones sociales de Serge Moscovici. Universidad de México. Athenea Digital, (2). Recuperado de http:// www.raco.cat/index.php/athenea/article/viewfile/34106/33945

Mosquera, C. (2002). Retos de la educación para la paz en Colombia: ¿De qué estamos hablando cuando hablamos de paz? La universidad piensa la paz: obstáculos y posibilidades. En Mosquera, C., Fajardo, F., y Díaz, C. (2002). La universidad piensa la paz: obstáculos y posibilidades. Universidad Nacional de Colombia. Programa de Iniciativas para la Paz y la Convivencia, PIUPC. Bogotá.

Muñoz, F. y Molina, B. (2010). Una Cultura de Paz compleja y conflictiva. La búsqueda de equilibrios dinámicos. Revista de Paz y conflictos, (3), 44-61. Recuperado de http://www.erevistas.csic.es/ficha_articulo.php?url=oai_revista508:63\&oai_iden=oai_revista508.

Naidú, M. (1986). Dimensions of peace. Peace Research, 18(2), 3-14.

Organización de las Naciones Unidas. (1999). Resolución 53/243. Declaración y Programa de Acción sobre una Cultura de Paz. Asamblea General de las Naciones Unidas. Recuperado de http://www.un.org/es/comun/ docs/?symbol=A/ RES/53/243

Organización de las Naciones Unidas. (2006). Resolución 61/45. Decenio Internacional de una cultura de paz y no violencia para los niños del mundo, 2001-2010. Asamblea General de las Naciones Unidas. Recuperado de http://www.un.org/es/comun/docs/?symbol=A/RES/61/45 
Otálvaro, G. y Páramo, P. (2006). Investigación alternativa: por una distinción entre posturas epistemológicas y no entre métodos. Cinta de Moebio. Recuperado de http://www.redalyc.org/articulo.oa?id=10102501

Palomera, R., Fernández-Berrocal, P., y Brackett, M. A. (2008). La inteligencia emocional como una competencia básica en la formación inicial de los docentes: algunas evidencias. Electronic journal of research in educational psychology, 6(15).

Panchón, C. (2007). Modelos educativos alternativos que conllevan el reconocimiento y el respeto por el otro. Revista de Educación, 1(342), 147-166. Recuperado de http://www.revistaeducacion.mec.es/re342/re342_08.pdf

Pantoja, A. y Díaz, M. (2009). Los proyectos "Escuela: espacio de paz" como propuestas integrales para la mejora de la convivencia en el ámbito escolar. Bordón. Revista de pedagogía, 61(2), 121-138. Recuperado de https://dialnet.unirioja.es/descarga/articulo/3004476.pdf

Pariente, J. y Perochena, P. (2013). Didáctica de la educación en valores en la ESO. Una propuesta utilizando las tecnologías para el aprendizaje y el conocimiento. Revista de Medios y Educación, 1(42), 195-208. Recuperado de http://acdc.sav.us.es/ pixelbit/images/stories/p42/15.pdf.

Parsons, W. (2007). Política social los derechos humanos como fin. Politicas públicas: una introducción a la teoría y la práctica. México: Flacso.

Pascual, A. y Yudkin, A. (2004). Educar para la convivencia escolar pacífica: principios y pautas en torno a por qué, para qué y cómo. Ponencia presentada en Primer Congreso para la Convivencia Pacífica Escolar. Cátedra Unesco de Educación para la Paz. Universidad de Puerto Rico. Recuperado de http://unescopaz.rrp.upr.

Pievi, N., y Echaverry Merino, E. (2008). Eventos históricos, memoria social, media y representaciones sociales. En V Jornadas de Sociología de la UNLP 10, 11 y 12 de diciembre de 2008. La Plata, Argentina. Universidad Nacional de La Plata. Facultad de Humanidades y Ciencias de la Educación. Departamento de Sociología.

Piñero, S. (2008). La teoría de las representaciones sociales y la perspectiva de Pierre Bourdieu: Una articulación conceptual. CPU-e, Revista de Investigación Educativa, 7. Recuperado de http://www.uv.mx/cpue/num7/ inves/pinero_representaciones_bourdieu.html

Quezada, V. (2004). Acerca de las competencias cognitivas. Revista Enfoques Educacionales, 6 (1), 67-73. Recuperado de http://www.facso.uchile.cl/ publicaciones/enfoques/08/Rodriguez_Quezada.pdf 
Reardon, B. (1978). El desarme y la educación para la paz. Perspectivas, 8(4), 443.

Reyzábal, M. (2012). Las competencias comunicativas y lingüísticas, clave para la calidad educativa. Revista Iberoamericana sobre Calidad, Eficacia y Cambio en Educación, 10 (4), 63-77. Recuperado de http://www.rinace. net/reice/numero h s/arts/vol10num4/art5.pdf

Rezola, R. (2011). Filosofía, ciudadanía y educación. Valencia: Asociación de la Filosofía para Niños y Niñas de la Comunidad Valenciana.

Ríos, C. (2000). Ciudadanos del mundo. Hacia una teoría de la ciudadanía. Revista Educación y Pedagogía. 12(28), 119-123.

Rodríguez, E. (2005). Metodología de la investigación. Villahermosa: Universidad Juárez Autónoma de Tabasco.

Romero, G. y Caballero, A. (2008). Convivencia, clima de aula y filosofía. Revista Electrónica Interuniversitaria de Formación del Profesorado, 11(3), 29-36. Recuperado de http://www.redalyc.org/articulo.oa?id=217015205004.

Ruiz, J. (2005). Pedagogía y educación ante el siglo XXI. Madrid: Universidad Complutense de Madrid.

Segovia, J., Gallego, J., García, I. y Rodríguez A. (2010). Competencias comunicativas de maestros en formación. Revista de Curriculum, 14(2), 303-323. Recuperado de http://www.ugr.es/ recfpro/rev142COL7.pdf

Souto, J. (2010). Contexto histórico y cuestiones actuales. Educación, democracia y ciudadanía. Madrid: Dikynson.

Tejada, A. (2007). Desarrollo y formación de competencias: un acercamiento desde la complejidad. Acción Pedagógica, 16(1), 40-47. Recuperado de http://www.saber.ula.ve/bitstream/123456789/17298/2/articulo4.pdf

Tobón, S., García, J. A., López, N. M., y Fernández, B. (2004). Estrategias didácticas para la formación de competencias. En IV Congreso Internacional Virtual de Educación (pp. 9-29). Recuperado de: www.uv.mx/ecoesad/cc.pdf

Torrego, J. (2010). La mejora de la convivencia en un instituto de educación secundaria de la comunidad de Madrid. Revista de Currículum y Formación de Profesorado, 14(1), 251-274.

Unesco. (2000). Desafíos de la educación. Diez módulos destinados a los responsables de los procesos de transformación educativa. Recuperado de http://unesdoc.unesco.org/images/0015/001591/159155s.pdf 
Unesco. (2009). Conocimiento complejo y competencias educativas. Recuperado de http://www.ibe.unesco.org/fileadmin/user_upload/Publications/ Working_Papers/knowledge_compet_ibewpci_8.pdf

Valdemoros, M., Ponce, A., Ramos, R. y Sanz, E. (2011). Pedagogía de la convivencia y educación no formal: un estudio desde el ocio físico-deportivo, los valores y la Familia. European Journal of Education and Psychology, 4(1), 33-49.

Vela-Peón, F. (2001). Observar, escuchar y comprender sobre la tradición cualitativa en la investigación social. México: Colegio de México - Flacso.

Vera, J. (2012). El concepto de identidad como recurso para el estudio de transiciones. Revista Psicologia \& Sociedades, 24(2), 272-282. Recuperado de: http://dialnet.unirioja.es/servlet/busquedadoc?t=identidad\&db=1\&td=todo

Vergara, E., Montaño, N., Becerra, R., León-Enríquez, O. y Arboleda, C. (2011). Prácticas para la formación democrática en la escuela: ¿Utopía o realidad? Revista Latinoamericana de Ciencias Sociales, Niñez y Juventud, 1(9), 227-253. Recuperado de http://dialnet.unirioja.es/servlet/busquedadoc?t=Participaci\%C3\%B3n++democr\% C3\%A1tica\&db=1\&td=todo

Vilà, R. (2003). El desarrollo de la competencia comunicativa intercultural en una sociedad multicultural y plurilingüe: una propuesta de instrumentos para su evaluación. Plurilingüisme i educació: els reptes del segle XXI. Ensenyar llengües en la diversitat i per la diversitat. Barcelona: ICE, 259-270.

Walzer, M. (1996). La política de la diferencia: estatalidad y tolerancia en un mundo multicultural. Recuperado de http://isegoria.revistas.csic.es/index.php/isegoria/article/view/210/210

Wiese, M. (1977). Compendium of wheat discases. St. Paul, American Phytopathological Society.

Zaitegi, N. (2010). La educación en y para la convivencia positiva en España. Reice. Revista Electrónica Iberoamericana sobre Calidad, Eficacia y Cambio en Educación. Recuperado de https://repositorio.uam.es/ handle/10486/661293 


\section{Sobre los autores}

\section{Ph.D. Audin Alonso Gamboa Suárez}

Doctor en Ciencias de la Educación (Rudecolombia - Universidad de Cartagena). Su actividad docente e investigativa se centra en la formación de maestros en el ámbito de los estudios sociales y la pedagogía para la paz. Actualmente es docente, tutor de la línea de pedagogía para la paz y la convivencia y director de la Maestría en Práctica Pedagógica de la Universidad Francisco de Paula Santander (Colombia). Se ha desempeñado como docente invitado del Doctorado en Desarrollo Educativo de la Universidad Pedagógica Nacional (México), Doctorado en Ciencias de la Educación de la Universidad de Cartagena (Colombia) y el Doctorado en Educación de la Universidad Santo Tomas (Colombia).

\section{Ph.D. Jesús Ernesto Urbina Cárdenas}

Doctor en Ciencias Sociales Niñez y Juventud (Cinde-Manizales), Decano de la Facultad de Educación, Artes y Humanidades de la Universidad Francisco de Paula Santander (Colombia). Su actividad docente e investigativa se centra en la formación de maestros en el 
ámbito de los estudios sociales y la pedagogía para la paz. Actualmente es coordinador de la línea de investigación en pedagogía para la paz y la convivencia de la Maestría en Práctica Pedagógica. Se ha desempeñado como docente invitado del Doctorado en Educación de la Universidad Santo Tomás (Colombia).

\section{Ph.D. José Arles Gómez Arévalo}

Universidad Santo Tomás Bogotá, su trayectoria investigativa se centra en la relación de la pedagogía, la ciencia y la espiritualidad liderando el grupo de investigación que lleva este nombre, actualmente dirige el Doctorado en Educación en la misma universidad. Es Licenciado en Teología con estudios de Posdoctorado de la Universidad Católica de Córdoba. Posdoctorado Universidad Santo Tomás en Ciencias Sociales, Educación e Interculturalidad, Doctorado en Teología de la Pontificia Universidad Urbaniana. Magíster en Filosofía Latinoamericana de la Universidad Santo Tomás. Master en Dirección General de la Universidad San Pablo. 



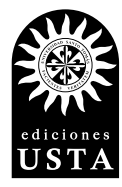

Esta obra se editó en Ediciones USTA,

Departamento Editorial de la Universidad Santo Tomás.

Se usó papel propalcote de 300 gramos para la carátula y papel bond beige de 75 gramos para páginas internas.

Tipografía de la familia Sabón.

Mayo de 2018 